\title{
Effect of preprocurement ventilation on lungs donated after cardiac death in a canine lung transplantation model.
}

\section{AUTHOR(S):}

Sakamoto, Jin; Chen, Fengshi; Yamada, Tetsu; Nakajima, Daisuke; Ohsumi, Akihiro; Kikuchi, Ryutaro; Zhao, Xiangdong; ... Sakai, Hiroaki; Bando, Toru; Date, Hiroshi

\section{CITATION:}

Sakamoto, Jin ...[et al]. Effect of preprocurement ventilation on lungs donated after cardiac death in a canine lung transplantation model.. Transplantation 2011, 92(8): 864870

\section{ISSUE DATE:}

2011-10-27

URL:

http://hdl.handle.net/2433/162547

\section{RIGHT:}

(c) 2011 Lippincott Williams \& Wilkins, Inc.; この論文は出版社版であり ません。引用の際には出版社版をご確認ご利用ください。; This is not the published version. Please cite only the published version. 
Effect of pre-procurement ventilation on lungs donated after cardiac death in a canine lung transplantation model

Jin Sakamoto, Fengshi Chen, Tetsu Yamada, Daisuke Nakajima, Akihiro Ohsumi, Ryutaro Kikuchi, Xiangdong Zhao, Takuji Fujinaga, Tsuyoshi Shoji, Hiroaki Sakai, Toru Bando, Hiroshi Date

Department of Thoracic Surgery, Graduate School of Medicine, Kyoto University

Key words: lung transplantation, ventilation, donation after cardiac death, canine model

\section{Abbreviations}

ADP: adenosine diphosphate

AMP: adenosine monophosphate

ANOVA: analysis of variance

AoP: aortic pressure

ATP: adenosine triphosphate

CO: cardiac output

CVP: central venous pressure

DCD: donation after cardiac death

ELISA: enzyme-linked immunosorbent assay

IL: interleukin

LAP: left atrial pressure

PIP: peak inspiratory pressure

PAP: pulmonary artery pressure

ROS: reactive oxygen species

RPL19: ribosomal protein L19

TNF: tumor necrosis factor 
TUNEL: terminal deoxynucleotidyltransferase-mediated dUTP nick-end labeling

WDR: wet-to-dry weight ratio

WIT: warm ischemic time 
Background: One method of countering chronic lung donor shortages is the practice of donation after cardiac death (DCD). However, this technique inevitably leads to pulmonary dysfunction related to warm ischemia. One promising method of alleviating this problem is ventilation. However, it can rarely be initiated from the onset of cardiac arrest, particularly in uncontrolled DCD donors. Here, we investigated the protective effect of the last 60 min of ventilation during a 240-min warm ischemic time. Methods: We rendered donor dogs cardiac-dead and left them at room temperature. Six dogs received ventilation with $100 \%$ oxygen for 60 min starting at 180 min after cardiac arrest (ventilation group). Eight dogs received no ventilation. Lungs were harvested $240 \mathrm{~min}$ after cardiac arrest, then transplanted into recipient dogs. At 60 min after reperfusion, the right pulmonary artery was ligated and the function of the left transplanted lung was evaluated. Results: In the ventilation group, all 6 animals survived for 240 min after reperfusion, while in the non-ventilation group, only 4 out of 8 survived. The ventilation group demonstrated significantly better pulmonary oxygenation, shunt fraction, and wet-to-dry weight ratio. Furthermore, the ventilation group revealed significantly higher levels of high-energy phosphates in the lung tissues, fewer apoptotic cells, lower levels of TNF- $\alpha$ and IL-8 mRNA in the lung tissues, and lower levels of IL-6 mRNA in the serum.

Conclusion: Our results suggest that ventilation during the late phase of the pre-procurement period may ameliorate ischemia-reperfusion injury in DCD donors. 


\section{Introduction}

Lung transplantation is currently the definitive treatment of end-stage respiratory disease. However, it is limited by a shortage of suitable donors. One potential solution to this problem is donation after cardiac death (DCD). Indeed, more than 100 cases of lung transplantations from DCD donors have been reported, at least 28 of which involved uncontrolled DCD donors (1).

Lung transplantation from DCD donors is feasible in part because the lung has a unique tolerance for ischemia; this is because lung cells are able to maintain aerobic metabolism by utilizing the oxygen in the alveoli even without perfusion (2). Some reports have already revealed that the lungs can be protected by inflation (2-4) or ventilation with oxygen $(4,5)$. For instance, a continuous 240-min ventilation and heparin use before cardiac arrest attenuated lung injury induced by 240-min of WIT in a canine transplantation model (5).

Although ventilation during the whole WIT is preferable, it is rarely possible to commence ventilation soon after cardiac arrest particularly in uncontrolled DCD donor. In order to determine the optimal technique for utilizing lungs from an uncontrolled DCD donor, we evaluated the protective effects of ventilation during the last 60 min of a $240-\mathrm{min}$ WIT in a canine lung transplantation model. This simulates a situation commonly encountered in clinical practice-a non-heparinized, uncontrolled DCD donor receiving ventilation during the last period of WIT.

\section{Results}

There were no significant differences between the treatment groups in donor or recipient weight (ventilation group vs. non-ventilation group, donor weight: $10.4 \pm 0.2$ vs. $10.1 \pm 0.4 \mathrm{~kg}$; recipient weight: $9.5 \pm 1.0$ vs. $9.0 \pm 0.4 \mathrm{~kg}$ ), or in total ischemic time (ventilation group vs. non- ventilation group: $422.8 \pm 9.2$ vs. $430.0 \pm 6.7 \mathrm{~min}$ ). We set $60 \mathrm{~min}$ for the implantation time in our protocol and could perform within 60 min. All 6 animals in the ventilation group survived until the end-point of the study (240 min after reperfusion), while only half (4/8) of the non- ventilation group survived. All 4 
dead animals expired as the result of a graft dysfunction; 3 of the deaths occurred between 75 and 120 min after reperfusion, while the fourth occurred between 120 and 180 min after reperfusion.

\section{Assessment of lung function}

$\mathrm{PaO}_{2}$ at $240 \mathrm{~min}$ after reperfusion was $619.5 \pm 49.1$ vs. $204.5 \pm 190.8 \mathrm{mmHg}$ (ventilation group vs. non-ventilation group). Furthermore, by repeated analysis of variance between groups, both $\mathrm{PaO}_{2}$ and pulmonary shunt fraction were significantly better in the ventilation group than in the non-ventilation group ( $P=0.0057$ and $P=0.010$, respectively; Table 1$)$. Peak airway pressure was higher in the non-ventilation group, but this difference did not reach significance $(P=0.072$, Table 1). Pulmonary artery pressure and pulmonary vascular resistance seemed high in the ventilation group, but these differences did not reach significance $(P=0.27$ and $P=0.33$, respectively; Table $1)$.

\section{Wet-to-dry lung weight ratio}

WDR at 240 min after reperfusion was significantly lower in the ventilation group than in the non-ventilation group (5.43 \pm 0.67 vs. $8.06 \pm 1.45$, respectively; $P=0.010)$.

\section{Measurement of adenine nucleotide levels}

In the ventilation group, ATP levels and energy charge were significantly improved by the 60-min ventilation $(P=0.0090$; Table $2 \mathrm{~B})$, though the improvements did not reach the levels observed in the normal lungs (Table 2A). Moreover, at 240 min after reperfusion, ATP and TAN $($ TAN $=$ ATP + ADP +AMP) levels were significantly higher in the recipient lungs of ventilation group than in the recipient lungs of the non-ventilation group $(P=0.019$ and 0.011 , respectively; Table $2 \mathrm{C})$ and the ATP and TAN levels improved similarly to those in the normal lungs (Table 2A), 
Macroscopic figures and histology

At 240 min after reperfusion, lungs from the non- ventilation group had dark-red areas exhibiting more patchiness than was observed in the ventilation group macroscopically (Figures 1A and 1C). The histological study indicated severe intraparenchymal hemorrhage and inflammation. (Figure 1B).

In situ apoptosis detection

At 240 min after reperfusion, there were significantly more TUNEL-positive cells in the non-ventilation group than in the ventilation group $(P=0.0019$; Figure 2$)$. This indicates that significantly more apoptosis occurred in the non-ventilation group.

\section{Serum cytokine levels}

At 75 min after reperfusion, TNF- $\alpha$ and IL-8 mRNA levels were significantly higher in the non-ventilation group than in the ventilation group $(P=0.0027$ and $P=0.032$, respectively; Figure 3A, D). Likewise, at 240 min after reperfusion, serum IL-6 levels were significantly higher in the non-ventilation group than in the ventilation group $(P=0.011$; Figure $3 \mathrm{~F})$.

\section{Discussion}

In the present study, we used a canine lung transplantation model to evaluate the protective effect of ventilation during "only the last 60 min" of a 240 -min WIT, while the previous studies revealed the protective effect of continuous ventilation in the whole WIT $(5,6)$. Our results indicated that the last 60 min of ventilation could preserve the lung function of an uncontrolled DCD donor. To be more specific, we observed better oxygenation, pulmonary shunt fraction, and wet-to-dry weight ratios in the ventilation treatment group. Furthermore, the ventilation group experienced significantly higher energy levels, better pathological findings, lower apoptosis, and lower levels of inflammatory 
cytokines.

The mechanism by which the 60-min ventilation provides protection can be inferred from our measurements of adenine nucleotide levels, apoptosis, and inflammatory cytokines. First, the adenosine nucleotide levels recorded here suggest that ventilation increased energy charge and ATP levels in the donor lungs, as well as ATP and TAN levels in the recipients. Previously, increased TAN levels have been significantly associated with lung viability (7). In non-ventilated or nitrogen-ventilated lungs retrieved 4 hours after death, $50 \%$ of the pulmonary parenchymal cells in alveolar areas of the lung were dead. However, oxygen ventilation in WIT resulted in attenuation of cell death: Viability was observed in more than $90 \%$ of cells in oxygen-ventilated lungs retrieved 4 hours after death and in $75 \%$ of cells from oxygen-ventilated lungs retrieved12 hours after arrest. Furthermore, depletion of ATP causes a decrease in the membrane potential of mitochondria (8), allowing calcium to escape and trigger the apoptotic process (9).

Second, we found significantly fewer apoptotic cells in the ventilation group, which we believe may have resulted in better pulmonary function after the transplant. Previous studies have produced conflicting evidence as to whether apoptotic cells have a deleterious impact on organ function. When the apoptotic cascade is blocked, injured cells may not always recover, leading to necrosis that is injurious to surrounding tissue (10). However, previous studies have shown a reduction in ischemia-reperfusion injury of kidney, heart and lung_after injection of antiapoptotic agents prior to reperfusion (11-13). Furthermore, it has been suggested that, in human lung transplantation, apoptosis may contribute to ischemia-reperfusion injury during the early phase of graft reperfusion and may be responsible for severe organ dysfunction (14).

Third, we observed significant decreases in the mRNA levels of the inflammatory cytokines TNF- $\alpha, I L-8$, and IL-6. Both anti- and pro-inflammatory cytokines, such as TNF- $\alpha$, interferon- $\mathrm{y}, \mathrm{IL}-1 \beta$, IL-2, IL-6, IL-8, 1L-9, and IL-10, are known to be released in response to lung ischemia reperfusion injuries (15-17). The characteristics of the early phase of ischemia-reperfusion injury depend on 
donor macrophages, which release IL-8, 12, 18, TNF- $\alpha$, and IFN- $\gamma$ (15). IL-8 in particular seems to influence graft failure after human lung transplantation $(18,19)$. Additionally, plasma levels of IL-6, IL-8, and TNF- $\alpha$ have been found to relate to endothelial dysfunction among apnea patients (20). Thus, in our study, it appears likely that the 60-min ventilation reduces donor macrophage activation and/or cytokine elevation in donor ischemic and non-ventilated lungs, thereby ameliorating endothelial dysfunction and the early phase of ischemia-reperfusion injury.

Ventilation with $100 \%$ oxygen is a double-edged sword. For instance, it may be toxic if performed beyond 6 hours (4). Further, a comparison of ventilation with room air, oxygen, and nitrogen revealed that ischemia-reperfusion injury in oxygen-ventilated animals was aggravated by oxygen free radicals (21). Other studies have reported that free radical scavengers such as superoxide dismutase can have protective effects against pulmonary ischemia-reperfusion injuries (22). Though we did not examine oxygen free radicals, we did find relatively high levels of pulmonary artery pressure and pulmonary vascular resistance in the ventilation group, which may have resulted from the activity of free radicals. In DCD donors ventilated with high-concentration oxygen, free radical scavengers may improve the outcomes. On the other hand, Fisher et al. found that hypoxia in alveoli resulted in a sharp decrease in ATP and a corresponding increase in the ATP degradation product hypoxanthine, which generates superoxide when oxygen is reintroduced via reperfusion and/or ventilation (23); this is consistent with our observations in the non-ventilation group. Reactive oxygen species (ROS) are generated with a decrease in the membrane potential of mitochondria which results from the ATP degradation (9). Therefore, we hypothesize that hypoxia-induced superoxide accumulation was responsible for the poor results observed in the non-ventilation group in our study. Moreover, from a clinical point of view, oxygen ventilation is used to simulate uncontrolled DCD donors-cardiopulmonary-resuscitation patients, in particular. American Heart Association guidelines call for the use of $100 \%$ oxygen during cardiopulmonary resuscitation (24). 
Other protective methods for uncontrolled DCD donors include in situ topical cooling (25-27), which was reported to have superior protection compared to ventilation_(28). However, ventilation is much easier and can be combined with medication, such as $\beta$-adrenergic agonists $(29,30)$, nitric oxide (31), and isoflurane (32) delivered through the airway. Cardiac arrest patients are usually ventilated during cardiopulmonary resuscitation; even if their lives cannot be saved, this technique has the added benefit of preparing their lungs for possible transplantation, the functions of which are estimated via ex vivo lung perfusion $(33,34)$, thus enlarging the donor pool.

One limitation of our study is that it has not investigated how long we could extend the WIT period with the final 60-min ventilation. Additionally, because we focused only on 60-min ventilations, we were not able to ascertain whether shorter ventilation periods would be adequate for preserving lung function. Additionally, our evaluation of the ventilated lungs was limited to 240 min after reperfusion. Finally, our study does not entirely mimic the clinical scenario in uncontrolled DCD donors in the following three points (35). First, these donors are ventilated within 30 min after cardiac arrest. Second, topical cooling is performed after declaration of death. Third, there is agonal phase leading to inflammation in the lungs prior to cardiac arrest. Further research will explore each of these remaining questions.

In conclusion, we found that the protective effect of ventilation during the last 60 min of a 240-min WIT preserves lung function of uncontrolled DCD donors. Thus, use of the ventilation during this period may improve our ability to manage uncontrolled DCD donors, thus increasing lung donor utilization.

\section{Materials and Methods}

\section{Animals}

Fourteen pairs of weight-matched TOYO Beagles $(8.35-11.9$ kg, Kitayama Labes Co. Ltd., Hongo Farm, Yamaguchi, Japan) were used in this study. All animals received humane care in compliance 
with the Principles of Laboratory Animal Care, formulated by the National Society for Medical

Research, and the Guide for the Care and Use of Laboratory Animals, prepared by the Institute of Laboratory Animal Resources and published by the National Institutes of Health (NIH Publication No. 86-23, revised 1996). The study protocol was approved by the ethics committee of the Graduate School of Medicine at Kyoto University, Japan.

\section{Donor preparation}

Donor dogs were anesthetized via an intramuscular injection of midazolam $(0.5 \mathrm{mg} / \mathrm{kg})$, xylazine $(0.25 \mathrm{mg} / \mathrm{kg})$, and atropine sulfate $(0.05 \mathrm{mg} / \mathrm{kg})$. They were then intubated and mechanically ventilated at a tidal volume of $25 \mathrm{ml} / \mathrm{kg}$ and a rate of $15 \mathrm{breaths} / \mathrm{min}$. The positive end-expiratory pressure was $5.0 \mathrm{~cm} \mathrm{H} \mathrm{H}_{2}$; the inspired $\mathrm{O}_{2}$ fraction was 1.0. The donors were maintained at an inhalation of $1 \%$ to $2 \%$ sevoflurane and an intravenous injection of vecuronium bromide $(0.4$ $\mathrm{mg} / \mathrm{kg} / \mathrm{hr})$ and buprenorphine hydrochloride $(0.01 \mathrm{mg} / \mathrm{kg} / \mathrm{hr})$. They were euthanized via an intravenous administration of potassium chloride $(0.5 \mathrm{mEq} / \mathrm{kg})$, without heparinization. The ventilators were removed and the tracheal tubes were open to room air. All donors were left at room temperature $\left(21^{\circ} \mathrm{C}\right)$ for $240 \mathrm{~min}$. The ventilation group $(\mathrm{n}=6)$ received ventilation with $100 \%$ oxygen for 60 min starting at 180 min after cardiac arrest. The non-ventilation group $(n=8)$ did not receive any ventilation for 240 min after cardiac arrest. A pulmonary arterial flush was performed on all donors at 240 min after the cardiac arrest, using ET-Kyoto solution (Otsuka Pharmaceutical Factory Inc, Tokushima, Japan), an extracellular preservation solution that we originally developed for clinical lung transplantation $(36,37)$. Prior to use, the ET-Kyoto solution was stored at $4^{\circ} \mathrm{C}$. For the antegrade flush, we used $100 \mathrm{ml} / \mathrm{kg} ; 50 \mathrm{ml} / \mathrm{kg}$ was used for the retrograde flush. Both were performed from $30 \mathrm{~cm}$ above the donors' chests. Ventilation was performed during the flush. The harvested organs, semi-inflated (within $20 \mathrm{~cm} \mathrm{H} \mathrm{H}_{2} \mathrm{O}$ ) with $100 \%$ oxygen, were preserved at $4^{\circ} \mathrm{C}$ for $120 \min$. 


\section{Recipient preparation and transplantation}

Recipient dogs were anesthetized, maintained, and ventilated in the same manner as the donors. Peak inspiratory pressure (PIP) was monitored by a pressure transducer that was attached to the tracheal tube. For each recipient, a 5F thermodilution catheter (151F7, Edwards Lifesciences, Irvine, CA, USA) was placed in the main pulmonary artery from the right femoral vein to measure pulmonary artery pressure (PAP), central venous pressure (CVP), and cardiac output (CO). A femoral arterial line was inserted for measuring aortic pressure (AoP) and for arterial blood gas analysis. After thoracotomy, a 2.0-mm catheter was inserted directly into the left atrium for monitoring left arterial pressure (LAP). We then performed a left pneumonectomy and left lung transplantation. We set 60 min for the implantation time The right pulmonary artery was encircled with a vascular tape and clamped with a tourniquet at 60 min after reperfusion in order to evaluate the function of the transplanted left lung.

\section{Pulmonary shunt fraction}

Pulmonary shunt fraction (Qs / Qt (\%)) was calculated according to the following formula: [Qs/Qt $(\%)=(\mathrm{Cc}-\mathrm{Ca}) /(\mathrm{Cc}-\mathrm{Cv}) \times 100]$, where $\mathrm{Cc}, \mathrm{Ca}$, and $\mathrm{Cv}$ represent the oxygen content of the pulmonary capillary blood, the pulmonary artery blood, and the pulmonary venous blood, respectively.

\section{Assessment of lung and cardiac function}

Arterial and pulmonary arterial blood samples were taken in order to analyze blood gases with a blood gas analyzer (iSTAT Portable Clinical Analyzer, iSTAT Corp., East Windsor, NJ, USA). 
Left lung tissues (100-300 mg) were used to calculate the wet-to-dry weight ratio (WDR) at $240 \mathrm{~min}$ after reperfusion or at death. The tissues were excised from the tip of the lung and the cut end was closed by ligation. Wet weight (mg) was measured first; dry weight (mg) was measured after the tissue had been dried overnight at $180^{\circ} \mathrm{C}$. The WDR was calculated by dividing the wet weight by the dry weight.

\section{Measurement of adenine nucleotide levels}

We used the pieces of peripheral lung tissues collected from "normal lungs", which were collected from left lungs of recipients just after the anesthetic induction. Furthermore, we used ones from donors before and after ventilation and from the recipients at $240 \mathrm{~min}$ after reperfusion. We measured levels of adenosine triphosphate (ATP), adenosine diphosphate (ADP), and adenosine monophosphate (AMP) using high-performance liquid chromatography (Shim-pack CLC-ODS column; $15 \mathrm{~cm} \times 6.0 \mathrm{~mm}$; Shimadzu, Japan). Total adenosine nucleotides (TAN) and energy charge were calculated as previously reported (30).

\section{Macroscopic figures and histology (hematoxylin and eosin staining)}

We recorded the macroscopic appearances of the left lungs 240 min after reperfusion. Left lung specimens collected 240 min after reperfusion were used for histological analysis. Each lung was immersed in $10 \%$ formalin, embedded in paraffin, and stained with hematoxylin and eosin.

In situ apoptosis detection (terminal deoxynucleotidyltransferase-mediated dUTP nick-end labeling (TUNEL) assay)

An apoptosis in situ detection kit (Wako Jyunyaku, Osaka, Japan) was used to evaluate nick-end labeling of DNA fragmentation in paraffin-embedded sections of left lungs harvested at 240 min after reperfusion or death, as previously reported (38). TUNEL-positive cells were counted in 10 
randomly chosen high-power fields per section at an original magnification of $400 \times$; apoptosis was expressed as the number of TUNEL-positive cells per section. Three separate investigators (J.S., F.C., and D.N.) evaluated, interpreted, and reached a consensus, without any knowledge of the experimental groups.

\section{Cytokine messenger RNA (mRNA) expression in lung tissues}

Left lung specimens collected at 75 min after reperfusion were stored in RNAlater TissueProtect tubes (Qiagen, Hiden, Germany) for RNA stabilization. Total RNA was extracted from specimens using an RNeasy Mini Kit (Qiagen), and the RNA extract was incubated with RNase-free DNase I (Qiagen) to remove contaminating DNA. Reverse transcription of total RNA was performed using Ready-To-Go You-Prime First-Strand Beads (GE Healthcare Bio-Sciences Corp, Piscataway, NJ, USA) to generate complementary DNA. We used oligonucleotide sequences originally described by Rachankonda et al. (39) and Koike et al. (40): interleukin (IL)-1ß (39), IL-6 (39), IL-8 (39), tumor necrosis factor (TNF)- $\alpha$ (39), and ribosomal protein L19 (RPL19) (40). Quantitative real-time reverse-transcription polymerase chain reactions (qRT-PCR) were performed on a LightCycler using LightCycler FastStart DNA masterPLUS SYBR Green I mix (Qiagen). PCR conditions were as follows: initial denaturation at $95^{\circ} \mathrm{C}$ for $10 \mathrm{~min}$, followed by 40 cycles of denaturation at $95^{\circ} \mathrm{C}$ for $30 \mathrm{~s}$, annealing at $55^{\circ} \mathrm{C}$ for $30 \mathrm{~s}$, and extension at $72^{\circ} \mathrm{C}$ for $30 \mathrm{~s}$. Quantities of the genes of interest were calculated from corresponding standard curves using LIGHTCYCLER software (Roche, Basel, Switzerland); they are presented here in relation to the amount of RPL19.

\section{Serum cytokine levels}

We used enzyme-linked immunosorbent assays (ELISA) to measure serum IL-6, IL-8, and TNF- $\alpha$ levels at 240 min after reperfusion in surviving animals. In all cases, we followed the instructions in the manufacturer's manuals from IL-6, IL-8, and TNF- $\alpha$ ELISA kits (Quantikine, R\&D Systems Inc., 
Minneapolis, MN, USA).

\section{Statistical analyses}

All statistical analyses were performed using STATVIEW v5.0 (Abacus Concepts, Inc., Berkeley, CA, USA). Values are expressed as means \pm standard deviations. We used Mann-Whitney U-tests and repeated-measures analysis of variance (ANOVA) tests to explore differences between and within treatment groups. Significance was defined as $P<0.05$. 


\section{References}

1. Dark JH. Lung transplantation from the non-heart beating donor. Transplantation 2008;86(2):200.

2. Date $\mathrm{H}$, Matsumura A, Manchester JK, et al. Evaluation of lung metabolism during successful twenty-four-hour canine lung preservation. J.Thorac.Cardiovasc.Surg. 1993;105(3):480.

3. Akashi A, Nakahara K, Kamiike W, et al. Attenuation of warm ischemic injury of rat lung by inflation with room air--assessment of cellular components and the surfactant in the bronchoalveolar lavage fluid in relation to changes in cellular adenosine triphosphate. Transplantation 1993;55(1):24.

4. Kuang JQ, Van Raemdonck DE, Jannis NC, et al. Pulmonary cell death in warm ischemic rabbit lung is related to the alveolar oxygen reserve. J.Heart Lung Transplant. 1998;17(4):406.

5. Ulicny KS,Jr, Egan TM, Lambert CJ,Jr, Reddick RL, Wilcox BR. Cadaver lung donors: effect of preharvest ventilation on graft function. Ann. Thorac.Surg. 1993;55(5):1185.

6. Wittwer T, Franke UF, Fehrenbach A, et al. Innovative pulmonary preservation of non-heart-beating donor grafts in experimental lung transplantation. Eur.J.Cardiothorac.Surg. 2004;26(1):144.

7. D'Armini AM, Tom EJ, Roberts CS, Henke DC, Lemasters JJ, Egan TM. When does the lung die? Time course of high energy phosphate depletion and relationship to lung viability after "death". J.Surg.Res. 1995;59(4):468.

8. Halestrap AP, Griffiths EJ, Connern CP. Mitochondrial calcium handling and oxidative stress. Biochem.Soc.Trans. 1993;21(2):353.

9. Brookes PS, Yoon Y, Robotham JL, Anders MW, Sheu SS. Calcium, ATP, and ROS: a mitochondrial love-hate triangle. Am.J.Physiol.Cell.Physiol. 2004;287(4):C817.

10. Hartmann A. Antiapoptotic agents in brain ischemia. N.Engl.J.Med. 2000;342(11):823.

11. Daemen MA, van 't Veer C, Denecker G, et al. Inhibition of apoptosis induced by ischemia-reperfusion prevents inflammation. J.Clin.Invest. 1999;104(5):541.

12. Yaoita H, Ogawa K, Maehara K, Maruyama Y. Attenuation of ischemia/reperfusion injury in rats by a caspase inhibitor. Circulation 1998;97(3):276.

13. Quadri SM, Segall L, de Perrot M, et al. Caspase inhibition improves ischemia-reperfusion injury after lung transplantation. Am.J.Transplant. 2005;5(2):292.

14. Fischer S, Cassivi SD, Xavier AM, et al. Cell death in human lung transplantation: apoptosis induction in human lungs during ischemia and after transplantation. Ann.Surg. 2000;231(3):424.

15. de Perrot M, Liu M, Waddell TK, Keshavjee S. Ischemia-reperfusion-induced lung injury. Am.J.Respir.Crit.Care Med. 2003;167(4):490.

16. Krishnadasan B, Naidu BV, Byrne K, Fraga C, Verrier ED, Mulligan MS. The role of proinflammatory cytokines in lung ischemia-reperfusion injury. J.Thorac.Cardiovasc.Surg. 2003;125(2):261.

17. Ng CS, Wan S, Arifi AA, Yim AP. Inflammatory response to pulmonary ischemia-reperfusion injury. Surg.Today 2006;36(3):205.

18. Fisher AJ, Donnelly SC, Hirani N, et al. Elevated levels of interleukin-8 in donor lungs is associated with early graft failure 
after lung transplantation. Am.J.Respir.Crit.Care Med. 2001;163(1):259.

19. De Perrot M, Sekine Y, Fischer S, et al. Interleukin-8 release during early reperfusion predicts graft function in human lung transplantation. Am.J.Respir.Crit.Care Med. 2002;165(2):211.

20. Lavie L, Polotsky V. Cardiovascular Aspects in Obstructive Sleep Apnea Syndrome - Molecular Issues, Hypoxia and Cytokine Profiles. Respiration 2009;78(4):361.

21. Koyama I, Toung TJ, Rogers MC, Gurtner GH, Traystman RJ. O2 radicals mediate reperfusion lung injury in ischemic O2-ventilated canine pulmonary lobe. J.Appl.Physiol. 1987;63(1):111.

22. Akao T, Takeyoshi I, Totsuka O, et al. Effect of the free radical scavenger $\mathrm{MCl}-186$ on pulmonary ischemia-reperfusion injury in dogs. J.Heart Lung Transplant. 2006;25(8):965.

23. Kelly RF. Current strategies in lung preservation. J.Lab.Clin.Med. 2000;136(6):427.

24. Neumar RW, Otto CW, Link MS, et al. Part 8: adult advanced cardiovascular life support: 2010 American Heart Association Guidelines for Cardiopulmonary Resuscitation and Emergency Cardiovascular Care. Circulation 2010;122(18 Suppl 3):S729.

25. Steen S, Ingemansson R, Budrikis A, Bolys R, Roscher R, Sjoberg T. Successful transplantation of lungs topically cooled in the non-heart-beating donor for 6 hours. Ann.Thorac.Surg. 1997;63(2):345.

26. Inci I, Arni S, Inci D, et al. Impact of topical cooling solution and prediction of pulmonary graft viability from non-heart-beating donors. J.Heart Lung Transplant. 2008;27(9):1016.

27. Snell Gl, Oto T, Lewey B, et al. Evaluation of techniques for lung transplantation following donation after cardiac death. Ann. Thorac.Surg. 2006;81(6):2014.

28. Rega FR, Jannis NC, Verleden GM, Flameng WJ, Lerut TE, Van Raemdonck DE. Should we ventilate or cool the pulmonary graft inside the non-heart-beating donor? J.Heart Lung Transplant. 2003;22(11):1226.

29. Jones DR, Hoffmann SC, Sellars M, Egan TM. Reduced ischemia-reperfusion injury with isoproterenol in non-heart-beating donor lungs. J.Surg.Res. 1997;69(2):385.

30. Chen F, Nakamura T, Fujinaga $T$, et al. Protective effect of a nebulized beta2-adrenoreceptor agonist in warm ischemic-reperfused rat lungs. Ann.Thorac.Surg. 2006;82(2):465.

31. Takashima S, Koukoulis G, Inokawa H, Sevala M, Egan TM. Inhaled nitric oxide reduces ischemia-reperfusion injury in rat lungs from non-heart-beating donors. J.Thorac.Cardiovasc.Surg. 2006;132(1):132.

32. Fujinaga T, Nakamura T, Fukuse $T$, et al. Isoflurane inhalation after circulatory arrest protects against warm ischemia reperfusion injury of the lungs. Transplantation 2006;82(9):1168.

33. Steen S, Sjoberg T, Pierre L, Liao Q, Eriksson L, Algotsson L. Transplantation of lungs from a non-heart-beating donor. Lancet 2001;357(9259):825.

34. Cypel M, Yeung JC, Hirayama S, et al. Technique for prolonged normothermic ex vivo lung perfusion. J.Heart Lung Transplant. 2008;27(12):1319.

35. de Antonio DG, Marcos R, Laporta R, et al. Results of clinical lung transplant from uncontrolled non-heart-beating donors. J.Heart Lung Transplant. 2007;26(5):529. 
36. Wada H, Fukuse T, Nakamura T, et al. ET-Kyoto solution for 48-hour canine lung preservation. Ann.Thorac.Surg. 1996;61(3):963.

37. Chen F, Nakamura T, Wada H. Development of new organ preservation solutions in Kyoto University. Yonsei Med.J. 2004;45(6):1107.

38. Zhang J, Chen F, Zhao X, et al. Nebulized phosphodiesterase III inhibitor during warm ischemia attenuates pulmonary ischemia-reperfusion injury. J.Heart Lung Transplant. 2009;28(1):79.

39. Rachakonda PS, Rai MF, Manning K, Schmidt MF. Expression of canine interleukin-4 in canine chondrocytes inhibits inflammatory cascade through STAT6. Cytokine 2008;44(1):179.

40. Koike T, Tsuchida M, Saitoh M, et al. Protective mechanism of ultrafiltration against cardiopulmonary bypass-induced lung injury. Transplant.Proc. 2009;41(9):3845. 


\section{Figure Legends}

Figure 1.

Results of macroscopic (A, C) and histological (B, D) analyses conducted 240 min after reperfusion (hematoxylin-eosin staining, original magnification $x 400$ ). In the non-ventilation group, we observed many dark-red spots $(\mathrm{A})$ and alveolar congestion, hemorrhage, infiltration, aggregation of inflammatory cells, and edema (B). However, the ventilation group looked relatively normal (C, D).

Figure 2.

TUNEL staining of lung sections harvested 240 minutes after reperfusion or death: (A) non-ventilation group; (B) ventilation group (original magnification $x 400$ ). Subjects in the non-ventilation group possessed significantly higher numbers of TUNEL-positive cell than subjects in the ventilation group (C). Data are presented as mean $\pm S D$ and were analyzed using a Mann-Whitney U-test. Non-Vent. = non-ventilation group; Vent. = ventilation group.

Figure 3.

Cytokine levels in the ventilation and non-ventilation groups at 2 different time points post-reperfusion. Cytokine messenger RNA (mRNA) expression in lungs at $75 \mathrm{~min}$ after reperfusion (A-D), with data normalized against ribosomal protein L19 (RPL19). mRNA expression of TNF- $\alpha$ and IL-8 was significantly higher in the non-ventilation group. Serum cytokine levels at 240 min after reperfusion (E-G). Serum levels of IL-6 was significantly higher in the non-ventilated group. Data are presented as mean \pm SD and were analyzed using a Mann-Whitney $U$-test. Non-Vent. $=$ non-ventilation group; Vent. = ventilation group . 
Table 1. Assessment of lung and cardiac function in surviving recipients in the non-ventilation $(n=4)$ and ventilation $(n=6)$ groups.

\section{Time after transplantation, min}

Before OP 0

Mean AoP, $\mathrm{mmHg}$

Non-vent.
Vent.
Mean PAP, mmHg

\section{Vent. \\ Mean CVP, $\mathrm{mmHg}$}

$17.5 \pm 3.8$

$$
19.0 \pm 3.5
$$

$19.7 \pm 3.6$

$19.1 \pm 1.9$

$20.3 \pm 2.9$

$31.0 \pm 11.9$

$33.5 \pm 11.5$

$33.7 \pm 16.3$

$32.5 \pm 12.3$

Non-vent. $\quad 5.5$
Vent. $\quad 5.5+2$ Mean LAP, mmHg

Non-vent. $\quad 13.5 \pm 1.9$

$15.5 \pm 2.5$

$15.5 \pm 2.3$

$8.7 \pm 1.2$

$7.7 \pm 0.9$

$8.3 \pm 2.5$

$8.6 \pm 4.4$

$0.8 \pm 0.0$

$0.6 \pm 0.1$

$0.7 \pm 0.1$

$0.9 \pm 0.2$

$0.7 \pm 0.1$

$0.8 \pm 0.2$

$0.7 \pm 0.1$

\begin{abstract}
$0.7 \pm 0.1$
\end{abstract}
$0.9 \pm 0.2$

$3160.1 \pm 2057.22850 .6 \pm 1467.52416 .9 \pm 1617.2$

Non-vent.

$382.2 \pm 299.0$

$352.1 \pm 329.6$

$431.1 \pm 425$

Vent.

$$
517.9 \pm 265.1
$$

$883.6 \pm 178.6$

$780.5 \pm 281.9$

$3624.0 \pm 1210.13281 .8 \pm 647.7$

$3018.1 \pm 896.5$

$3105.0 \pm 1269.8 \quad 0.33$

$\mathrm{PaO} 2, \mathrm{mmHg}$

Non-vent.
Vent.
PaCO2, mmHg

Non-vent.

$$
21.1 \pm 1.5
$$

$22.9 \pm 4.2$

$23.2 \pm 5.0$

$32.1 \pm 6.0$

$43.3 \pm 7.0$

$53.2 \pm 9.4$

$60.4 \pm 18.2$

Vent.

$23.9 \pm 4.6$

$22.6 \pm 3.2$

$22.9 \pm 3.0$

$33.8 \pm 7.0$

$38.6 \pm 7.9$

$37.6 \pm 4.2$

$38.3 \pm 6.3$

0.12

Peak airway pressure, $\mathrm{mmHg}$

\begin{tabular}{lrlllllll} 
Non-vent. & $15.7 \pm 2.5$ & $14.7 \pm 2.7$ & $14.7 \pm 2.7$ & $19.0 \pm 5.7$ & $19.0 \pm 4.9$ & $20.0 \pm 6.0$ & $20.5 \pm 5.4$ \\
Vent. & $15.1 \pm 1.1$ & $13.5 \pm 1.3$ & $12.8 \pm 2.2$ & $14.6 \pm 1.0$ & $14.1 \pm 1.6$ & $14.3 \pm 1.0$ & $14.6 \pm 1.0$ & 0.072 \\
Pulmonary shunt fraction, \% & & & & & & & \\
Non-vent. & $5.7 \pm 3.8$ & $7.7 \pm 7.1$ & $6.3 \pm 3.4$ & $10.3 \pm 10.6$ & $23.4 \pm 26.8$ & $28.6 \pm 21.6$ & $36.5 \pm 27.9$ \\
Vent. & $6.3 \pm 3.0$ & $3.7 \pm 2.2$ & $2.5 \pm 1.6$ & $2.9 \pm 2.8$ & $2.1 \pm 2.0$ & $3.1 \pm 4.0$ & $3.4 \pm 3.5$ & 0.010 \\
\hline
\end{tabular}

$\mathrm{OP}=$ operation; $\mathrm{AoP}=$ aortic pressure; $\mathrm{PAP}=$ pulmonary artery pressure $\mathrm{CVP}=$ central venous pressure; $\mathrm{LAP}=$ left atrial pressure; $\mathrm{PVR}=$ pulmonary vascular resistance. Data are shown as mean \pm SD. $P$-values are for the differences between groups by repeated measures analysis of variance 
Table 2. Energy levels in normal lung (A), in donors before and after the 60-min ventilation (B), and in recipients at $240 \mathrm{~min}$ after reperfusion (C).

A

\begin{tabular}{ll}
\hline Energy levels & Normal lung \\
\hline ATP $(\mathrm{nmol} / \mathrm{mg} \cdot \mathrm{dw})$ & $3.25 \pm 0.66^{\mathrm{a}}$ \\
Energy charge $^{\mathrm{b}}$ & $0.73 \pm 0.02$ \\
TAN $^{\mathrm{c}}(\mathrm{nmol} / \mathrm{mg} \cdot \mathrm{dw})$ & $5.05 \pm 0.73$ \\
\hline
\end{tabular}

B

\begin{tabular}{llll}
\hline Energy levels & Before ventilation & After ventilation & $P$-value \\
\hline ATP & $0.66 \pm 0.11$ & $1.71 \pm 0.34$ & 0.0090 \\
Energy charge & $0.35 \pm 0.03$ & $0.63 \pm 0.03$ & 0.0090 \\
TAN & $2.64 \pm 0.35$ & $3.19 \pm 0.51$ & 0.17 \\
\hline
\end{tabular}

C

\begin{tabular}{llll}
\hline Energy levels & Ventilation group & Non-ventilation group & $P$-value \\
\hline ATP & $3.64 \pm 0.50$ & $2.52 \pm 0.54$ & 0.019 \\
Energy charge & $0.82 \pm 0.02$ & $0.83 \pm 0.03$ & 0.52 \\
TAN & $4.88 \pm 0.55$ & $3.33 \pm 0.53$ & 0.011 \\
\hline
\end{tabular}

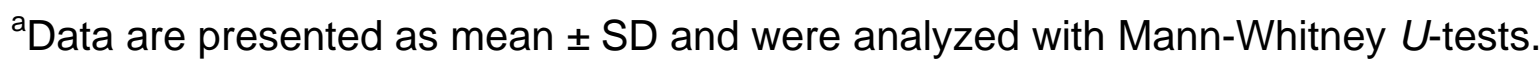

${ }^{b}$ Energy charge $=(A T P+0.5 A T P) /(A T P+A D P+A M P)$.

${ }^{\mathrm{C}} \mathrm{TAN}=\mathrm{ATP}+\mathrm{ADP}+\mathrm{AMP}$.

$\mathrm{ADP}=$ adenosine diphosphate; $\mathrm{AMP}=$ adenosine monophosphate; $\mathrm{ATP}=$ adenosine triphosphate;

TAN $=$ total adenosine nucleotides. 


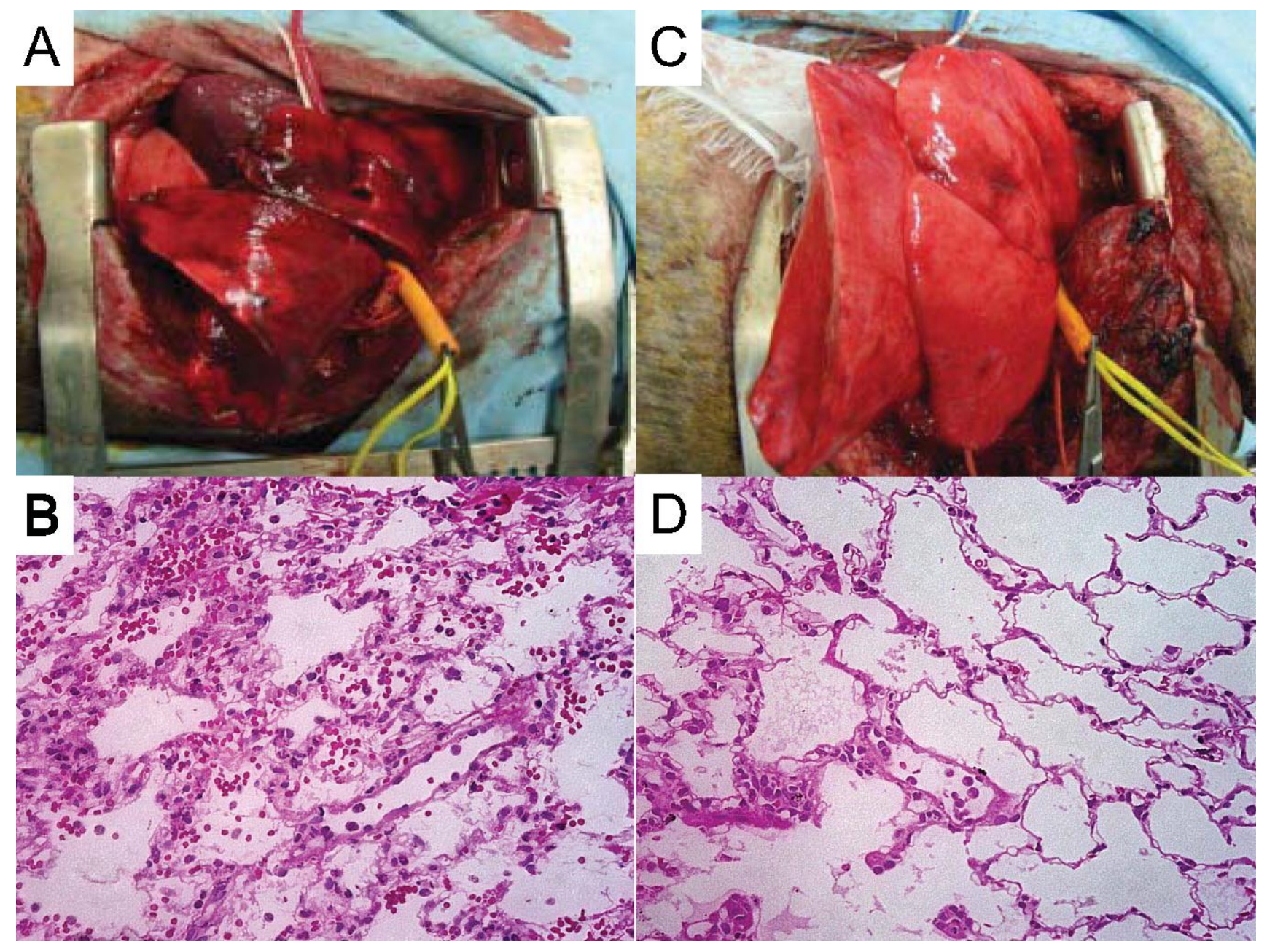

Figure 1. 

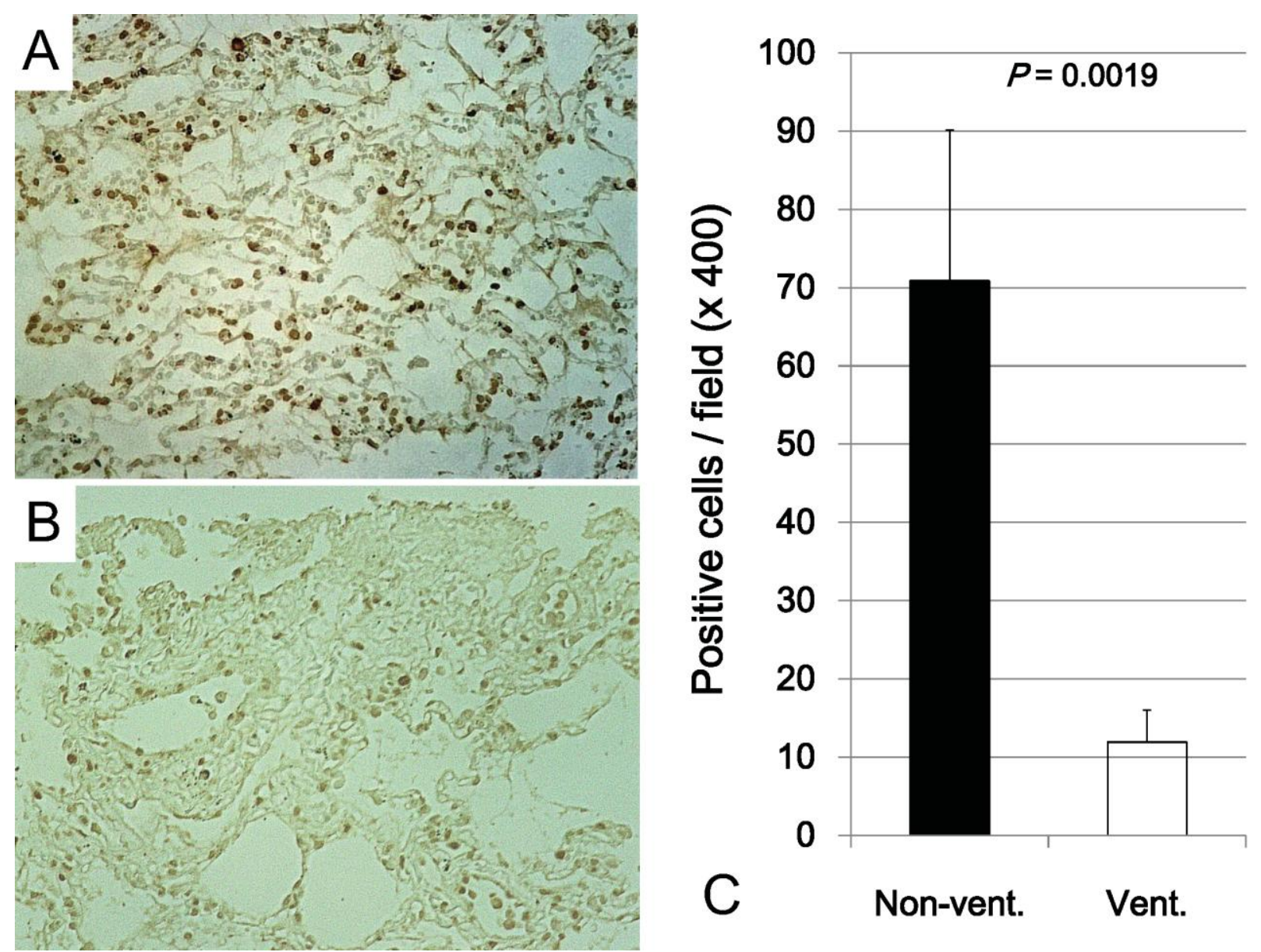

Figure 2. 

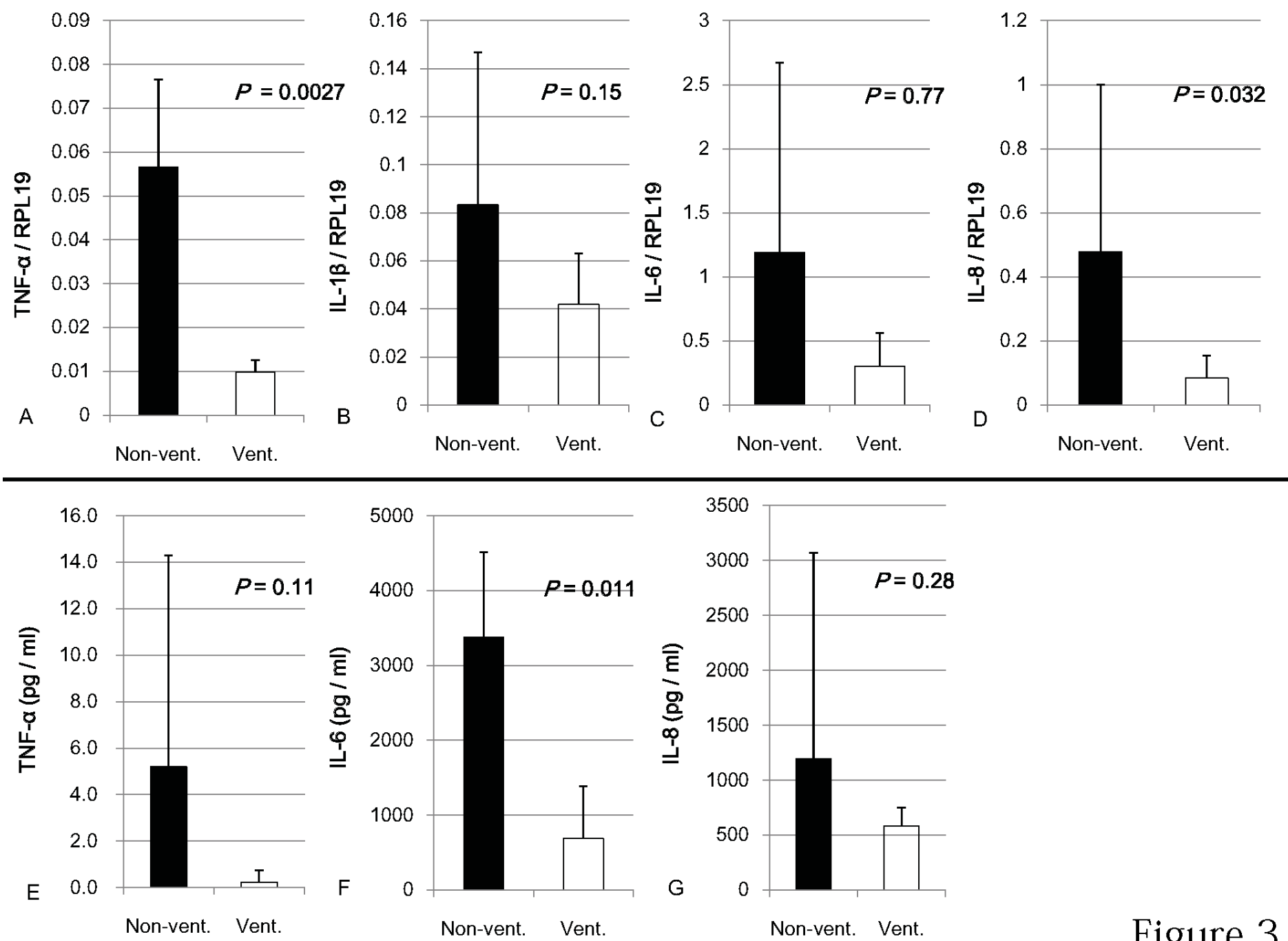

Figure 3. 